\title{
A Cross Sectional Study of Serum Thyroid Stimulating Hormone and Lipid Function in Women
}

\author{
Sudhina P.S. ${ }^{1}$ \\ ${ }^{1}$ Department of Physiology, Government T.D. Medical College, Alappuzha, Kerala, India.
}

ABSTRACT

\section{BACKGROUND}

Menopause is an unavoidable stage in a women's life. This may lead to various emotional, metabolic and hormonal changes. Hypothyroidism is seen to be common among post-menopausal women these days. Menopause also may lead to various lipoprotein abnormalities.

\section{METHODS}

80 women were included in this study. They were divided into 2 groups - 40 postmenopausal women and 40 premenopausal women. Serum thyroid stimulating hormone (S.TSH) and lipid profile values were determined. Total cholesterol (TC) / high density lipoprotein (HDL) ratio was $3.77 \pm 0.98$ in premenopausal women and $5.97 \pm 0.98$ in post-menopausal women respectively. Low density lipoprotein (LDL) / HDL ratio was $2.22 \pm 0.84$ in premenopausal women and $4.37 \pm 0.94$ in postmenopausal women. Correlation coefficient between S.TSH and serum cholesterol was 0.116, between S.TSH and TC / HDL was 0.09 and between S.TSH and LDL / HDL was 0.09 .

\section{RESULTS}

Serum cholesterol / HDL ratio, LDL / HDL ratio is significantly higher in postmenopausal women. In post-menopausal women, levels of TSH and serum cholesterol were found to be positively correlated and this is found to be statistically significant. In post-menopausal women, the levels of S.TSH and serum cholesterol / HDL ratio were found to be positively correlated and this is found to be statistically significant. In post-menopausal women, the levels of S.TSH and LDL / HDL ratio were found to be positively correlated and this is found to be statistically significant.

\section{CONCLUSIONS}

This study showed a hypothyroid tendency for the post-menopausal women. Screening for S.TSH and serum lipid profile may be advised for every woman in the perimenopausal age group so that the related problems during menopausal transition can be reduced.

\section{KEY WORDS}

TSH, Lipid Function, Premenopausal Women, Post-Menopausal Women
Corresponding Author: Dr. Sudhina P.S., Department of Physiology, Government T.D Medical College, Alappuzha, Kerala, India. E-mail:sudhinaps@yahoo.co.in

DOI: $10.14260 /$ jemds/2021/15

How to Cite This Article: Sudhina PS. A cross sectional study of s.tsh and lipid function in women. $J$ Evolution Med Dent Sci 2021;10(02):74-78, DOI: $10.14260 / \mathrm{jemds} / 2021 / 15$

Submission 23-07-2020,

Peer Review 14-11-2020,

Acceptance 20-11-2020,

Published 11-01-2021.

Copyright (C) 2021 Sudhina P.S. This is an open access article distributed under Creative Commons Attribution License [Attribution 4.0 International (CC BY 4.0)] 


\section{BACKGROUND}

Menopause is the final cessation of menstruation which usually occurs between the ages of 45 to 50 years. It is generally a change of life. The last few cycles are irregular and anovulatory and menstruation finally stops. When compared to reproductive age woman, gonadotrophin levels throughout the menopause are significantly elevated. The result of these hormonal changes is often manifested by deleterious physical, psychological and sexual changes in post-menopausal phase.

Some women show emotional instability, irritability or depression or vasomotor disturbances called hot flushes. It is the flushing of skin of face and neck with feeling of warmth followed by sweating. After menopause there is gradual progressive atrophy of gonads and accessory sex organs. Breasts may shrink due to gradual atrophy of glandular part. Due to absence of oestrogen, chances of osteoporosis also there. ${ }^{1}$ Menopause may also lead to various lipoprotein abnormalities. Oestrogen is having a protective role against coronary artery heart disease. This is mainly by its action on lipoprotein metabolism and by its direct action on vessel wall. There are beneficial effects exerted by oestrogen on lipoprotein metabolism which are due to direct hepatic action. Oestrogen also increase the number of HDL receptors in liver. It increases catabolism of circulating LDL molecules. All these lipid parameters are assessed by estimating serum lipid profile.

Menopause has a direct impact on the activity of the thyroid gland. During the menopause there is imbalance in the oestrogen and progesterone hormone levels that may in turn have a drastic impact on the thyroid hormone production. The thyroid gland might have some kind of disturbances in working and secretion of the thyroid hormone. Imbalance of the hormonal level may lead to either hypothyroidism or hyperthyroidism. Thyroid hormone regulates wide array of metabolic parameters. Thyroid stimulating hormone induces 3-hydroxy-3-methyl-glutaryl-coenzyme A reductase (HMG Co A) which is the $1^{\text {st }}$ step of cholesterol biosynthesis and it can alter the lipoprotein metabolism. So, correlation between S.TSH and serum lipid profile is assessed to detect what type of alteration occurs in lipid profile. ${ }^{2}$ The chance of cardiovascular disease ${ }^{3}$ is more in women over age 50 .

The risk of atherosclerosis in women increases significantly after menopause. ${ }^{4}$ The risk of atherosclerosis is 3.4 times greater in post-menopausal women. Three types of lipids that have been linked to cardiovascular disease and atherosclerosis are cholesterol and its carrier proteins LDL (low density lipoprotein) and HDL (high density lipoprotein). ${ }^{5}$ The risk for cardiovascular disease decreases by $3 \%$ for each $1 \%$ reduction in serum cholesterol. ${ }^{6}$ In different studies, levels of serum cholesterol is increased significantly to 1 to 2 years after menopause. ${ }^{7}$ After menopause, the lipid levels change towards a less cardio protective pattern than before menopause. This study was done to find out any correlation between S.TSH and various lipid values.

\section{METHODS}

This was a cross sectional observational study done for one year from December 2009 to December 2010. Two study groups were selected; forty premenopausal women in the reproductive age group and forty post-menopausal women attending medicine outpatient department with prior informed consent. Exclusion criteria were subjects with known thyroid disease and subjects having diabetes, hypertension and heart disease. Screening of all subjects for the study was done using proforma. Samples of blood were taken by phlebotomy method after an overnight fast of twelve hours using syringes and needles which are disposable. $8 \mathrm{ml}$ blood was collected from anti cubital vein under aseptic precautions and transferred to bottles. Serum TSH and all parameters of lipid profile were estimated and analysed.

S.TSH measured using an automated chemiluminescence analyser. Estimation of total cholesterol was done using cholesterol reagent set. This is based on enzymatic method. Estimation of HDL cholesterol also done by enzymatic method. The estimation of triglyceride was done using the ready to use liquid triglyceride reagent kit. LDL cholesterol was estimated indirectly using Friedewald formula. The value of serum cholesterol, triglyceride and HDL cholesterol estimated earlier is applied in their formulas to obtain the corresponding LDL cholesterol values.

$$
\mathrm{LDL}-\mathrm{C}=\mathrm{TC}\left(\frac{H D L-C+\text { Triglyceride }(\mathrm{mg} / \mathrm{dl})}{5}\right)
$$

Estimation of very low-density lipoprotein (VLDL) cholesterol was calculated using the formula.

$\mathrm{VLDL}-\mathrm{C}=\left(\frac{\text { Triglyceride }(\mathrm{mg} / \mathrm{dl})}{5}\right)$

Total cholesterol divided by HDL cholesterol and LDL cholesterol divided by HDL cholesterol also calculated.

\section{Statistical Analysis}

Statistical analysis has been done to determine the difference between two groups. The results are given in tables and figures. Statistical package for social sciences (SPSS) was used to analyse data. The results of the study were given as mean \pm standard deviation. Determination of significance of difference between two groups that are compared is done by applying student's t test. The level of significance was taken as P value of $<0.05$.

\section{RESULTS}

\begin{tabular}{|ccc|}
\hline Age & $\begin{array}{c}\text { Premenopausal } \\
\text { Women }\end{array}$ & Post-Menopausal Women \\
$20-29$ & 8 & - \\
$30-39$ & 13 & - \\
$40-49$ & 18 & - \\
$50-59$ & 1 & 30 \\
$60-69$ & - & 10 \\
\hline \multicolumn{3}{c}{ Table 1. Age Distribution } \\
\hline
\end{tabular}

Forty-five percentage of premenopausal women selected for the study were aged between 40 - 49 years. Seventy-five percentage of postmenopausal women were of the age 60 to 69 years. 


\section{TSH and Lipids}

The mean value of S.TSH was $2.63 \pm 3.05$ in pre-menopausal group and $3.93 \pm 3.77$ in post-menopausal group. The mean value of serum cholesterol $(\mathrm{mg} / \mathrm{dl}$ ) in premenopausal group was $177.27 \pm 27.63$ and that of post-menopausal women was $244.9 \pm 55.42$.

\begin{tabular}{|ccc|}
\hline & $\begin{array}{c}\text { Pre-Menopausal } \\
\text { Women }\end{array}$ & $\begin{array}{c}\text { Post-Menopausal } \\
\text { Women }\end{array}$ \\
\hline Mean & 3.77 & 5.97 \\
SD & 0.98 & 0.98 \\
\hline \multicolumn{2}{|c|}{ Table } & 2. Comparison of Total Cholesterol / HDL Ratio \\
& in Pre- and Post-Menopausal Women \\
\hline $\mathrm{p}$ Value $<0.05$ & & \\
\hline
\end{tabular}

There is significant difference between TC / HDL ratios of premenopausal and post-menopausal women

\begin{tabular}{|ccc|}
\hline & $\begin{array}{c}\text { Pre-Menopausal } \\
\text { Women }\end{array}$ & $\begin{array}{c}\text { Post-Menopausal } \\
\text { Women }\end{array}$ \\
\hline Mean & 2.22 & 4.37 \\
SD & 0.84 & 0.94 \\
\hline & Table 3. Comparison of LDL / HDL Ratio in \\
& Pre- and Post-Menopausal Women \\
\hline $\mathrm{p}$ Value $<0.05$ & \multicolumn{2}{c}{} \\
\hline
\end{tabular}

There is significant difference between LDL / HDL ratios of premenopausal and post-menopausal women

\section{Correlation}

In order to find out whether there is a significant association present or absent between the continuous variables, coefficient of correlation ( $\mathrm{r}$ ) was calculated. Correlation coefficient tends to lie between +1.0 and - 1.0. If $r$ is nearing + 1 , indicating strong positive association. If $r$ is nearing 1 , indicating strong negative association. The level of significance was taken as $P$ value of $<0.05$.

\begin{tabular}{|cccccc|}
\hline $\begin{array}{c}\text { Pre- } \\
\text { Menopause }\end{array}$ & $\begin{array}{c}\text { Correlation } \\
\text { Coefficient Value }\end{array}$ & $\begin{array}{c}\text { Post- } \\
\text { Menopause }\end{array}$ & $\begin{array}{c}\text { Correlation } \\
\text { Coefficient }\end{array}$ & $\begin{array}{c}\mathbf{p} \\
\text { Value }\end{array}$ \\
$\begin{array}{c}\text { S.TSH \& } \\
\text { S. Cholesterol }\end{array}$ & 0.116 & $>0.05$ & $\begin{array}{c}\text { S.TSH \& } \\
\text { S. Cholesterol }\end{array}$ & 0.326 & $<0.05$ \\
S.TSH \& S.HDL & -0.038 & $>0.05$ & S.TSH \& S.HDL & -0.060 & $>0.05$ \\
S.TSH \& S.VLDL & 0.121 & $>0.05$ & S.TSH \& S.VLDL & 0.073 & $>0.05$ \\
S.TSH \& S.LDL & -0.003 & $>0.05$ & S.TSH \& S.LDL & 0.311 & $>0.05$ \\
S.TSH \& S.TGL & 0.1 & $>0.05$ & S.TSH \& S.TGL & 0.034 & $>0.05$ \\
$\begin{array}{c}\text { S.TSH \& LDL / } \\
\text { HDL }\end{array}$ & 0.09 & $>0.05$ & S.TSH \& LDL / HDL & 0.3 & $>0.05$ \\
S.TSH \& TC / HDL & 0.09 & $>0.05$ & S.TSH \& TC / HDL & 0.3 & $>0.05$ \\
\hline Table 4. Correlation Coefficients were Calculated between S. TSH \\
Levels and Various Lipid Parameters
\end{tabular}

\section{Post-Menopausal Women}

1) The levels of S.TSH \& serum cholesterol found to be positively correlated in post-menopausal women and this is found to be statistically significant, i.e., when one parameter increases other also increases.

2) In post-menopausal women the levels of S.TSH and serum cholesterol / HDL ratio found to be positively correlated and this is found to be statistically significant.

3) The levels of S.TSH and LDL / HDL ratio found to be positively correlated in post-menopausal women and this is found to be statistically significant.
4) In post-menopausal women correlation between TSH \& HDL, TSH \& triglycerides, TSH \& VLDL and TSH \& LDL were found to be statistically insignificant.

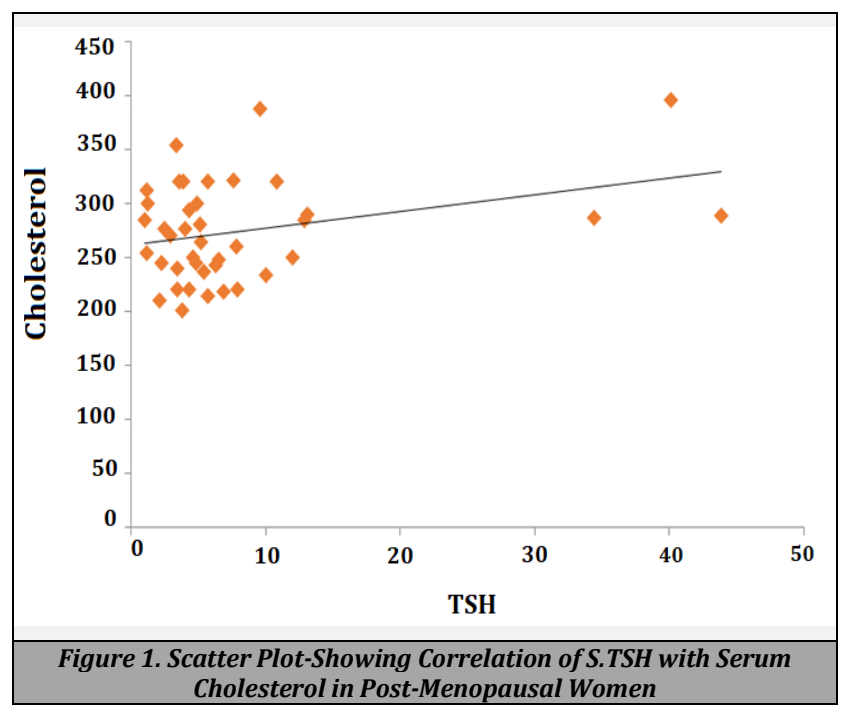

\section{Premenopausal Women}

In premenopausal women correlation between TSH \& serum cholesterol, TSH \& HDL, TSH \& triglycerides, TSH \& VLDL, TSH \& LDL, TSH \& TC / HDL ratio, TSH \& LDL / HDL ratio were found to be statistically insignificant.

\section{DISCUSSION}

Menopause is permanent cessation of menstruation caused by ovarian failure. Usually occurs at an average age of 52 years, within a range of 40 to 58 years. Even though life expectancy of women has increased, the age of menopause has not changed. This means a woman has to spend greater than one third of her life after menopause. Age of menopause also has a genetic determination.

During menopause, there will be changes in the hypothalamic and pituitary hormones indicating ovarian failure. Ovarian follicles will be depleted in the ovary secondary to apoptosis. Response of ovary to pituitary folliclestimulating hormone (FSH) and luteinizing hormone (LH) will be poor and the production of oestrogen and progesterone from ovary will cease.

Oestrogen deficiency is the cause of clinical consequences of menopause and impact of oestrogen deficiency and aging is difficult to distinguish. Main concerns of menopausal women include vasomotor symptoms, genitourinary syndrome of menopause, sexual dysfunction, osteoporosis, cancer, cardiovascular disease and cognitive decline. In about $75 \%$ of women, vasomotor symptoms will be present. Hot flashes can affect daily activities, disrupt sleep and may disturb the working women. Thyroid disease incidence also increases, therefore there is need of doing thyroid function tests.

Genitourinary disturbances will be secondary to oestrogen deficiency. Main symptoms will be genital irritation, dryness and burning, dysuria, urinary urging, and recurrent urinary tract infections. About $66 \%$ of women will be affected by osteoporosis. 
This study was conducted to compare and correlate the relation between serum levels of TSH and lipid profile in normal healthy menopausal women and in healthy women of reproductive age group before menopause.

LDL / HDL cholesterol and total / HDL cholesterol ratios can be taken as indicators of risk in cardiovascular disease. They are having high predictive value than other parameters particularly total / HDL cholesterol ratio. ${ }^{8}$ In women, total cholesterol level should be less than $200 \mathrm{mg} / \mathrm{dl}$, ideal LDL cholesterol level should be less than $70 \mathrm{mg} / \mathrm{dl}$ and HDL cholesterol level close to $50 \mathrm{mg} / \mathrm{dl}$.

Total / HDL cholesterol ratio is calculated by dividing total cholesterol value by HDL cholesterol value. The ratio would be below 5, ideally 3.5. Higher ratios indicate a higher risk of heart disease.

In my study, total cholesterol / HDL ratio is $3.77 \pm 0.98$ in premenopausal women and $5.97 \pm 0.98$ in post-menopausal women. Values are higher in post-menopausal group and this difference was found to be statistically significant. In postmenopausal group TC / HDL levels are above 5, showing more risk towards cardiovascular disease.

In my study, LDL / HDL ratio is $2.22 \pm 0.84$ in premenopausal women and $4.37 \pm 0.94$ in post-menopausal women. There is considerable difference between LDL / HDL ratio levels of premenopausal and post-menopausal women. Here also ratio is more in post-menopausal group hinting towards risk for cardiovascular disease.

A positive correlation was obtained between S.TSH and serum cholesterol levels in post-menopausal women, which was statistically significant. This was consistent with the following studies; thyroid hormones and lipid metabolism in a group of patients over seventy, ${ }^{9}$ thyroid stimulating hormone and its correlation with lipid profile in the obese Nepalese population, 10 thyroid function and perimenopausal lipid and weight changes, ${ }^{11}$ thyroid functions and serum lipids in older women. ${ }^{12}$ Here they found that increasing levels of TSH was associated with linear increase in lipid concentrations.

"Thyroid function tests, serum lipids and gender interrelations in a middle-aged population",13 found out that there is a correlation between TSH and lipids mainly in the females. Thyroid function and lipid sub particle sizes in patients with short-term hypothyroidism in a populationbased cohort ${ }^{14}$ was done to determine whether lipoprotein sub particle concentrations are associated with thyroid status in hypothyroid women, there is a shift toward less atherogenic large LDL, small VLDL, and large HDL sub particle sizes

A study of association of thyroid stimulating hormone and coronary lipid risk factors with lipid per oxidation in hypothyroidism ${ }^{15}$ was done and conclusion was that increased levels of TSH may be considered as an index of the severity of hypothyroidism and also of the extent of the associated lipid peroxidation.

"Lipid Profile Alterations in Subclinical Hypothyroidism"16 study concluded that subclinical hypothyroidism has association with increased cholesterol and triglyceride levels and high total cholesterol / HDL and LDL / HDL ratios.

"Effects of Thyroid Dysfunction on Lipid Profile"17 in Greece showed that thyroid dysfunction was seen in altered lipid profile. Other studies also proved relation between thyroid and atherosclerosis.18-19 Study on "Effects of Thyroid Dysfunction on Lipid Profile" showed thyroid dysfunction can have important effects on lipid profile. Study showed an increase in HDL, triglycerides, total cholesterol and LDL-C in patients with hypothyroidism. ${ }^{20}$ "Serum lipids in hypothyroidism" showed significant correlation between raised TSH levels \& serum total cholesterol and LDL-C respectively. ${ }^{21}$

There is a positive correlation between S.TSH and serum cholesterol / HDL levels in post-menopausal women and it is statistically significant. So as TSH increases, the cardiovascular risk also increases. Effect of changes of TC / HDL ratio is explained in study; total cholesterol / HDL cholesterol ratio vs. LDL cholesterol / HDL cholesterol ratio as indices of ischemic heart disease. ${ }^{22}$ In middle-aged women C / HDL-C ratio can be taken as a powerful predictor of acute myocardial infarction. ${ }^{23}$

Effect of LDL / HDL ratio was also explained in various studies. $^{24}$ In my study a positive correlation was obtained between S.TSH and LDL / HDL levels in group of women after menopause and that is statistically significant also. There was no statistically significant correlation between S.TSH and other parameters of lipid profile in group of women after menopause. In premenopausal women correlation between S.TSH and serum lipid profile was not statistically significant.

This study showed a hypothyroid tendency for the postmenopausal women. So routine screening of post-menopausal women for thyroid status is advisable, since this can decrease the possible incidence of hypothyroidism in these women. Screening for S.TSH and serum lipid profile may be advised for every woman in the perimenopausal age groups so that the related problems during menopausal transition can be reduced. TSH and lipids are correlated positively, so treatment for hypothyroidism may help in decreasing cardiovascular risk.

\section{CONCLUSIONS}

A statistically significant positive correlation was seen between S.TSH and serum cholesterol levels in postmenopausal women. A statistically significant positive correlation was observed between S.TSH and serum cholesterol / HDL ratio levels in post-menopausal group of women. A statistically significant positive correlation was obtained between S.TSH and LDL / HDL ratio levels in postmenopausal group of women. A statistically significant correlation was not seen between S.TSH and other parameters of lipid profile in post-menopausal group. A statistically significant correlation was not seen between S.TSH and any parameters of lipid profile in the premenopausal women.

Data sharing statement provided by the authors is available with the full text of this article at jemds.com.

Financial or other competing interests: None.

Disclosure forms provided by the authors are available with the full text of this article at jemds.com.

\section{REFERENCES}

[1] Subrahmanyam S, Madhavankutty K, Singh HD. Textbook of human physiology. $6^{\text {th }}$ edn. New Delhi: S. Chand 2006.

[2] Yen SS. The biology of menopause. J Reprod Med 1977;18(6):287-96. 
[3] U.S. Department of Health, education and welfare: framing- hamstudy. (publication no:74) Washington, DS, 1974.

[4] Witteman JC, Grobbee DE, Kok FJ, et al. Increased risk of atherosclerosis in women after menopause. BMJ 1989;298(6674):642-4.

[5] Steinberg D. Lipoproteins and the pathogenesis of atherosclerosis. Circulation 1987;76(3):508-14.

[6] Lipid research clinical program: The lipid research clinics coronary primary prevention trial results. II. The relationship of reduction in incidence of coronary heart disease to cholesterol lowering. JAMA 1984;251(3):36574.

[7] Lindquist 0. Intraindividual changes of blood pressure, serum lipids and body weight in relation to menstrual status: results from a prospective Population study of women in Goteberg Sweden. Prev Med 1982;11(2):16272.

[8] Millán J, Pinto X, Muñoz A, et al. Lipoprotein ratios: physiological significance and clinical usefulness in cardiovascular prevention. Vasc Health Risk Manage 2009; 5:757-65.

[9] Maugeri D, Santangelo A, Barbagallo P, et al. Thyroid hormones and lipid metabolism in a group of patients over seventy. Eur Rev Med Pharmacol Sci 1999;3(5):2116.

[10] Nagila A, Bhatt M, Poudel B, et al. Thyroid Stimulating Hormone and its Correlation with Lipid Profile in the Obese Nepalese Population 2008;2(4):932-7.

[11] Massoudi MS, Meilahn EN, Orchard TJ, et al. Thyroid function and perimenopausal lipid and weight changes: The Thyroid Study in Healthy Women (TSH-W). J Womens Health 1997;6(5):553-8.

[12] Bauer DC, Ettinger B, Browner WS. Thyroid functions and serum lipids in older women: a population-based study. Am J Med 1998;104(6):546-51.

[13] Petersson U, Kjellstrom T. Thyroid function tests, serum lipids and gender interrelations in a middle-aged population. Scand J Prim Health Care 2001;19(3):183-5.
[14] Pearce EN, Wilson PWF, Yang Q, et al. Thyroid function and lipid subparticle sizes in patients with short-term hypothyroidism and a population-based cohort. J Clin Endocrinol Metab 2008;93(3):888-94.

[15] Nanda N, Bobby Z, Hamide A. Association of thyroid stimulating hormone and coronary lipid risk factors with lipid peroxidation in hypothyroidism. Clin Chem Lab Med 2008;46(5):674-9.

[16] Monica C, Costa A, Santos M, et al. Lipid Profile Alterations in Subclinical Hypothyroidism. The Endocrinologist 2004;14(3):121-5.

[17] Rizos CV, Elisaf MS, Liberopoulos EN. Effects of thyroid dysfunction on lipid profile. Open Cardiovasc Med J 2011; 5:76-84.

[18] Cappola AR, Ladenson PW. Hypothyroidism and atherosclerosis. The Journal of Clinical Endocrinology and Metabolism 2003;88(6):2438-44.

[19] Biondi B. Cardiovascular effects of mild hypothyroidism. Thyroid 2007;17(7):625-30.

[20] Rizos CV, Elisaf MS, Liberopoulos EN. Effects of thyroid dysfunction on lipid profile. Open Cardiovasc Med J 2011; 5:76-84.

[21] Prakash A, Lal AK. Serum lipids in hypothyroidism: our experience. Indian J Clin Biochem 2006;21(2):153-5.

[22] Lemieux I, Lamarche B, Couillard C, et al. Total cholesterol / HDL cholesterol ratio vs LDL cholesterol / HDL cholesterol ratio as indices of ischemic heart disease risk in men: the Quebec Cardiovascular Study. Arch Intern Med 2001;161(22):2685-92.

[23] Calling S, Johansson SE, Wolff M, et al. The ratio of total cholesterol to high density lipoprotein cholesterol and myocardial infarction in Women's health in the Lund area (WHILA): a 17-year follow-up cohort study. BMC Cardiovasc Disord 2019;19(1):239.

[24] Panagiotakos DB, Pitsavos C, Skoumas J, et al. Importance of LDL/HDL cholesterol ratio as a predictor for coronary heart disease events in patients with heterozygous familial hypercholesterolaemia: a 15-year follow-up (1987-2002). Curr Med Res Opin 2003;19(2):89-94. 